\title{
INICIAÇÃO ESPORTIVA EM CADEIRA DE RODAS: ESTRUTURAÇÃO DE UM PROGRAMA PARA CRIANÇAS COM DEFICIÊNCIA FÍSICA ${ }^{1}$
}

Flávio Anderson Pedrosa Melo

Universidade Federal de São Carlos, São Carlos, São Paulo, Brasil

Mey Abreu van Munster

Universidade Federal de São Carlos, São Carlos, São Paulo, Brasil

\begin{abstract}
Resumo
O estudo em questão teve o objetivo de descrever um programa de iniciação esportiva em cadeira de rodas voltado a crianças com deficiência física com idade entre seis e dez anos. Trata-se de um estudo descritivo com base empírica, por meio do qual foi possível obter como resultados as etapas estruturantes do programa, conforme detalhamento: compreensão da condição físico-motora do participante; adaptação à cadeira de rodas; elaboração dos objetivos do programa; reconhecimento dos espaços; seleção dos conteúdos programáticos; planejamento das estratégias de ensino; estrutura das aulas. Concluiu-se que os pressupostos adotados para a construção do programa demonstraram ser adequados às características, necessidades e interesses do público em questão.
\end{abstract}

Palavras-chave: Educação Física; Iniciação Esportiva; Deficiência Física; Habilidades Motoras

\section{Introdução}

As crianças e jovens com deficiências físicas, na maior parte dos casos, não são encorajadas a levar uma vida ativa e de fato tendem a adotar um estilo de vida sedentário, devido às muitas barreiras para participar e/ou praticar atividades físicas (LONGMUIR; BAR-OR, 2000; SHAPIRO; MARTIN, 2010). A não participação pode acarretar em complicações ulteriores relacionadas aos aspectos motores, fisiológicos e à saúde, as quais poderiam ser atenuadas ou evitadas por meio da apropriação de um estilo de vida ativo, que envolve não somente o indivíduo, mas seus familiares, professores e demais pessoas ao seu redor.

Fatores como: o não encorajamento por parte dos familiares, por questões de segurança e/ou superproteção; professores que não se consideram capacitados a trabalhar com esta população devido à sua formação; o desinteresse da própria criança no tocante à sua participação esportiva por razões como o medo de lesões; o insucesso ou bullying por parte dos colegas (MORAN; BLOCK, 2010) e ainda questões relacionadas às barreiras de acessibilidade (RIMMER et al., 2005) são alguns dos aspectos responsáveis pela não participação da criança com deficiência em atividades físicas e esportivas.

\footnotetext{
${ }^{1}$ O presente estudo contou com o apoio do Conselho Nacional de Desenvolvimento Científico e Tecnológico (CNPq).
} 
Os principais efeitos positivos proporcionados pelo esporte, quando atrelado às pessoas com deficiências físicas apontados pelos estudos, fazem alusão à melhora na realização das atividades de vida diária, autoconceito, não só em relação à melhora de sua condição física (aumento da resistência e força) e/ou psicológica (diminuição da ansiedade e depressão, aumento da autoestima e autoeficácia), mas também no concernente a maiores oportunidades de relações interpessoais. (MARTIN; SMITH, 2002; MARTIN, 2006; GORGATTI, 2008; SERNAGLIA; DUARTE; DALLA DÉA, 2010).

Ainda referindo-se aos efeitos das atividades físicas para a pessoa com deficiência, Shapiro e Martin (2010) mencionam que os benefícios obtidos por jovens com deficiências físicas engajados nos esportes e atividades físicas também estão ligados a aspectos psicossociais, dentre os quais se encontram as relações interpessoais e ampliação do círculo social (MARTIN; SMITH, 2002), bem como o aumento da diversão, prazer durante sua participação (MARTIN, 2006) e, capacitação para consumação da sua participação no esporte (MARTIN, 1999). Por vezes a pessoa com deficiência permanece excluída das oportunidades de praticar exercícios físicos e da possibilidade de manutenção de hábitos saudáveis.

Portanto, a oferta de informações sobre os hábitos saudáveis decorrentes da prática de exercícios físicos para crianças, jovens e adultos com deficiências físicas pode vir a encorajálos a buscar novas chances de participação em atividades que lhes auxiliem na descoberta de suas capacidades físicas, seja por meio de programas de atividade física ou das modalidades esportivas adaptadas (ARBOUR et al., 2007). Diante disso, são variadas as finalidades de participação em programas de atividades físicas e esportivas direcionados às pessoas com deficiência.

Para muitas crianças o momento especial em sua vida diária é poder brincar/jogar/divertir-se com seus amigos. Assim como para os pais e familiares é importante observar suas crianças praticando alguma atividade física e/ou esportiva. Os efeitos positivos da participação em esportes durante a juventude podem ser tão valiosos para as crianças com deficiência, como são para as crianças sem deficiência. No entanto, infelizmente, muitas crianças, em particular as com deficiências mais complexas, entre as quais se incluem alguns casos de deficiência física, são excluídas da participação em atividades físicas e esportivas durante o período da infância (MORAN; BLOCK, 2010), impossibilitando as vivências motoras típicas dessa fase.

A criança precisa ser estimulada durante todas as fases do seu desenvolvimento motor. De acordo com a teoria desenvolvimentista, na fase de movimentos especializados, o período transitório $^{2}$ é a fase em que o movimento torna-se uma ferramenta aplicável a diversas e complexas atividades da vida diária, onde as habilidades estabilizadoras, locomotoras e manipulativas são refinadas, elaboradas e combinadas para uso nas diversas situações (GALLAHUE; OZMUN, 2005).

Devido à intensidade de vivências motoras típicas desse período de descobertas, a criança é capaz de intensificar sua aprendizagem relativa às habilidades motoras (GALLAHUE; OZMUN, 2005). Assim, essa é uma fase propícia para incentivar as crianças a participarem de uma grande variedade de esportes. É importante que todas as crianças, inclusive as com deficiência, desenvolvam as habilidades motoras fundamentais antes que as habilidades esportivas específicas sejam introduzidas (HIGGS, 2011).

Portanto, durante o estágio de iniciação, as crianças devem participar de programas de treinamento de baixa intensidade, em que a ênfase se encontra no divertimento, centrados no desenvolvimento esportivo geral e não em uma modalidade esportiva específica (BOMPA, 2002).

\footnotetext{
${ }^{2} \mathrm{O}$ período transitório contém elementos pertencentes aos movimentos fundamentais, porém possuem forma, precisão e controle maiores (GALLAHUE; OZMUN, 2005).
} 
Diante do exposto, buscou-se desenvolver um programa voltado à estimulação das habilidades motoras fundamentais de locomoção, estabilização e manipulação na cadeira de rodas, por meio dos aspectos pedagógicos e educacionais, utilizando-se de brincadeiras e jogos pré-desportivos que possibilitem aquisições necessárias para desenvolvimento de atividades físicas esportivas em cadeiras de rodas, em crianças com deficiência física.

Esse trabalho é parte de uma pesquisa mais abrangente, a qual buscou analisar a influência de um programa de iniciação esportiva em crianças com deficiência física (MELO, 2014). Todavia, nesse momento foi feito um recorte desse estudo com o intuito de apresentar o processo de elaboração de um programa aplicado a crianças com deficiência física de iniciação esportiva em cadeira de rodas, dada a escassez de referências e estudos voltados a essa temática.

\section{Método}

O trabalho em questão possui caráter qualitativo, sendo caracterizado como um estudo descritivo com base empírica. Os estudos descritivos têm como procedimento indagar a incidência e os valores em que se manifestam uma ou mais variáveis, medir, situar e/ou observar um grupo de pessoas, situações, fenômenos e descrevê-los detalhadamente (SAMPIERI; COLLADO; LUCIO, 2013). A intervenção aqui exposta teve como públicoalvo crianças com deficiência física (comprometimento de membros inferiores), de ambos os gêneros e faixa etária entre seis e dez anos de idade.

O programa de iniciação esportiva teve duração de oito semanas, três sessões/aulas por semana, perfazendo um total de 24 sessões em um período de dois meses. Cada uma das sessões teve duração média de 50 minutos.

A observação sistemática foi utilizada como instrumento de coleta de dados, baseada em um roteiro previamente estruturado e elaborado pelos autores (MARCONI; LAKATOS, 2008, p. 82). Por meio da observação, foi possível registrar os acontecimentos ocorridos durante o período de intervenção para posterior análise. A partir desses registros, procedeu-se uma análise de dados do tipo descritiva, por meio da qual foram estabelecidas as etapas estruturantes do programa de ensino em questão, as quais apresentadas nos resultados.

Cabe informar que o estudo em questão foi aprovado pelo Comitê de Ética em Pesquisa da Universidade Federal de São Carlos - CEP/UFSCar, sob parecer de $\mathrm{n}^{\circ} 72038$, de acordo com as prerrogativas da resolução 466/12 da Comissão Nacional de Ética em Pesquisa (CONEP).

\section{Resultados e discussão}

Para o desenvolvimento de um programa de iniciação esportiva voltado a crianças com deficiência física, existe a necessidade de se percorrer algumas etapas, dentre as quais se encontram: compreensão da condição físico-motora do participante; adaptação dos participantes às cadeiras de rodas esportivas; estabelecimento dos objetivos do programa; reconhecimento dos espaços; seleção dos conteúdos programáticos; planejamento das estratégias de ensino utilizadas; estrutura das aulas, as quais serão apresentadas e discutidas a seguir:

\section{Condição físico-motora do participante}

Inicialmente, é essencial que o professor procure estabelecer aproximação com o participante e/ou com seus responsáveis. Durante a entrevista inicial é importante transmitir 
segurança aos responsáveis acerca dos procedimentos a serem seguidos, bem como o domínio sobre sua temática e área de atuação.

Foram aplicadas anamneses visando obter informações sobre cada um dos participantes para uma melhor compreensão da condição físico-motora deles, fornecer informações acerca das finalidades, responder a eventuais dúvidas e questionamento, estabelecer aos horários e cronograma para desenvolvimento do programa.

Nesse momento buscou-se obter informações sobre o participante, referente a aspectos como: histórico de vida, etiologia (tipo e nível de comprometimento, bem como o tempo de manifestação da deficiência); aspectos relacionados à saúde e possíveis comorbidades ocasionadas pela lesão (como infecções, úlceras por pressão, cirurgias), recursos utilizados como forma de locomoção (variados tipos de próteses e órteses), ao contexto familiar e social, condições socioeconômicas, informações sobre as experiências anteriores com a prática de atividades físicas e esportivas, bem como das atividades desenvolvidas pelo participante na sua vida diária. Essas informações são utilizadas para melhor planejamento e controle da intervenção, diminuindo os riscos de influências de variáveis externas.

\section{Adaptação dos participantes às cadeiras de rodas esportivas}

Um dos princípios básicos para a realização de um programa de iniciação esportiva para crianças com deficiência física consiste em compreender a utilização das cadeiras de rodas esportivas. Cabe ressaltar que muitas das crianças com deficiências físicas fazem uso de bengalas, muletas e andadores, entre outros dispositivos auxiliares, para locomoção diária. Não necessariamente crianças com comprometimentos nos membros inferiores estão acostumadas ao uso de cadeiras de rodas convencionais em seu dia a dia. Portanto, há um processo de adaptação ao uso desse dispositivo de locomoção.

Nesse momento foram apontados alguns fatores importantes que devem ser considerados, tais como os tipos, características, prescrição e finalidades de uso desse equipamento, em associação às características dos participantes.

Referindo-se aos tipos de cadeiras de rodas e suas particularidades, Carvalho (2006) descreve as diferentes características e variedades desses dispositivos: cadeiras de rodas de uso permanente, de uso temporário, higiênicas, de recreação, para uso clínico (ortostáticas), cadeiras posturais e cadeiras de rodas para atividades esportivas. $\mathrm{O}$ autor menciona que essas são utilizadas como dispositivos auxiliares de locomoção e devem ser prescritas visando atender as necessidades e objetivos específicos de cada pessoa.

É de suma importância que a prescrição de uma nova cadeira de rodas corresponda às expectativas atuais do usuário, preferências, necessidades físicas, funcionais e exigências que emergem de suas interações com o meio ambiente (BATAVIA; BATAVIA; FRIEDMAN, 2001). Os usuários de cadeira de rodas necessitam que ela seja funcional para sua utilização diária, mas que também preencha seus anseios. Uma cadeira de rodas é mais que um simples dispositivo de locomoção para pessoas com deficiência física, pois pode representar as suas aspirações e por vezes sua personalidade.

A prescrição de cadeira de rodas é uma intervenção intrinsecamente complexa. Essa complexidade surge a partir da relação entre as três variáveis de uma prescrição para cadeiras de rodas: o usuário de cadeira de rodas, suas necessidades, habilidades e preferências; a tecnologia disponível e as exigências do meio onde ela será utilizada (BATAVIA; BATAVIA; FRIEDMAN, 2001; DI MARCO; RUSSEL; MASTERS, 2003). De acordo com os autores, essas três variáveis são dinâmicas e influenciam uma à outra de maneira contínua. 
As cadeiras de rodas esportivas apresentam modelos apropriados às características das diferentes modalidades esportivas, propiciando maior leveza e desempenho. $\mathrm{O}$ design e dispositivos de segurança permitem manobras eficientes, proporcionando maior performance ao usuário. Cambagem nas rodas traseiras, materiais leves empregados em sua construção e a personalização das medidas de acordo com a classificação funcional do usuário, possibilitam a prática de modalidades como basquetebol, tênis, tênis de mesa, corrida, dança, handebol e outras atividades recreativas.

Diversas técnicas e conceitos atribuídos às cadeiras esportivas foram tomados como referência para o aperfeiçoamento da cadeira de uso diário (CARVALHO, 2006).

\section{Estabelecimento dos objetivos do programa}

Determinar os objetivos do programa é uma etapa indispensável, uma vez que os direcionamentos do programa, público-alvo, serviços prestados e demais aspectos devem balizar todo o seu desenvolvimento. No caso específico do Programa de Iniciação Esportiva para crianças com Deficiência Física, esse teve como finalidade desenvolver as habilidades motoras fundamentais de locomoção, estabilização e manipulação na cadeira de rodas, por meio dos aspectos pedagógicos e educacionais, utilizando-se de brincadeiras e jogos prédesportivos que possibilitem aquisições necessárias para desenvolvimento de atividades físicas esportivas em cadeiras de rodas, em crianças com deficiência física.

\section{Reconhecimento prévio do local}

Torna-se imprescindível o reconhecimento prévio do local onde será desenvolvido o programa. Essa etapa deve considerar as características do público envolvido, uma vez que as condições de acesso e permanência devem ser adequadas. Deve-se observar a existência de barreiras arquitetônicas que dificultem ou impeçam a participação de pessoas com deficiências físicas, idosos ou pessoas com demais comprometimentos em seu aparelho locomotor. Diante disso, o professor deve reconhecer o espaço de trabalho para evitar o constrangimento do participante, evitando a necessidade de transportá-los nos braços, e buscando possibilitar a independência do participante em seu deslocamento até o local da prática.

\section{Seleção dos conteúdos programáticos}

Um Programa de Iniciação Esportiva para crianças com Deficiência Física deve levar em consideração as características individuais de cada um dos participantes (etiologia da deficiência, contraindicações, utilização ou não de medicamentos controlados, limitações e potencialidades etc.). Sobretudo, deve considerar os interesses, expectativas e o potencial da criança, independentemente da condição de deficiência. A partir da identificação das necessidades específicas do integrante o professor será capaz de planejar o programa de ensino, considerando a ordem de aplicação dos conteúdos, as especificidades de cada componente de maneira a aperfeiçoar as potencialidades deste, mesmo que as atividades venham a ser aplicadas em grupo.

$\mathrm{O}$ desenvolvimento motor de uma criança durante sua infância está associado às oportunidades e experiências motoras que lhes são proporcionadas. De acordo com Gallahue e Ozmun (2005, p. 368) "o desenvolvimento de habilidades motoras especializadas é altamente dependente de oportunidades para a prática, encorajamento, ensino de qualidade e o contexto ecológico do ambiente". Essas são variáveis que devem ser consideradas quando se busca atingir um desenvolvimento motor fundamental maduro. 
Ainda para Gallahue e Ozmun, (2005, p. 368) "O desenvolvimento motor maduro é pré-requisito para incorporação bem sucedida das habilidades motoras especializadas, as quais correspondem ao repertório motor de um indivíduo". Logo, a fase de desenvolvimento das habilidades motoras fundamentais, relacionadas ao período transitório entre os sete e dez anos de idade é essencial nesse processo de desenvolvimento. Todavia, a maior parte das crianças com seis anos têm potencial para executar desempenhos no estágio maduro de grande parte dos padrões motores fundamentais (GALLAHUE; OZMUN, 2005).

Essas habilidades podem vir a ser adquiridas por meio da aplicação de atividades lúdicas que envolvam tais habilidades motoras fundamentais, representadas pelos fundamentos específicos das diversas modalidades esportivas, utilizando-se de jogos e brincadeiras de caráter cooperativo, pré-desportivos adaptados, entre outros dependendo o objetivo que se queira alcançar.

Na faixa etária dos seis aos dez anos, as crianças não fixam a atenção por muito tempo e são voltadas para a ação, sendo assim, não conseguem permanecer paradas, ouvindo, por muito tempo. Portanto, é imprescindível que as aulas sejam bastante criativas e diversificadas durante esse período, enfatizando a participação e o divertimento acima da vitória (BOMPA, 2002).

Assim, torna-se imprescindível tornar as atividades atrativas aos participantes, tentando desenvolver as habilidades motoras e os fundamentos específicos de maneira combinada, como meio de potencializar as necessidades e capacidades dos participantes do programa.

Para a estruturação e planejamento das intervenções do Programa de Iniciação Esportiva foram utilizados jogos e brincadeiras lúdicas englobando as habilidades motoras fundamentais (Locomotoras, Manipulativas e Estabilizadoras), as quais se apresentavam inseridas nas atividades por meio dos fundamentos específicos da diferentes modalidades esportivas adaptadas (passe, recepção, arremesso, drible e mobilidade e deslocamento sobre a cadeira de rodas) desenvolvidas no decorrer do programa.

A estruturação estabelecida para desenvolvimento das intervenções foi dividida em quatro momentos, descritos no quadro 1:

Quadro 1 - Descrição da estrutura das sessões

\begin{tabular}{cl}
\hline $\begin{array}{c}\text { ESTRUTURA DAS } \\
\text { SESSÕES }\end{array}$ & \multicolumn{1}{c}{ DESCRIÇÃO } \\
\hline $\begin{array}{c}\text { CONVERSA INICIAL E } \\
\text { ALONGAMENTO }\end{array}$ & $\begin{array}{l}\text { Fase de preparação do corpo para o desenvolvimento das } \\
\text { atividades, acompanhadas do alongamento e conversas a } \\
\text { respeito das atividades desenvolvidas na aula anterior; }\end{array}$ \\
\hline DESENVOLVIMENTO & $\begin{array}{l}\text { O desenvolvimento consistiu o momento de aplicação das } \\
\text { atividades propriamente ditas, momento de aprimoramento } \\
\text { das habilidades por meio de jogos e brincadeiras; }\end{array}$ \\
\hline INTERVALO & $\begin{array}{l}\text { A parada para hidratação consistiu no período de diminuição } \\
\text { do ritmo das atividades, onde os participantes teriam cinco } \\
\text { minutos para tomar água e descansar. Após esse período } \\
\text { eram retomadas as atividades; }\end{array}$ \\
\hline VOLTA À CALMA & $\begin{array}{l}\text { A volta à calma foram os instantes de feedback dos } \\
\text { participantes, momento de discussão referente às atividades } \\
\text { aplicadas, onde eles poderiam expor suas dúvidas e contar o } \\
\text { que aprenderam. }\end{array}$ \\
\hline
\end{tabular}

Fonte: Melo (2014). 
A estrutura utilizada nas sessões foi assim estabelecida buscando organizar o processo de aprendizagem, a partir de uma formatação de planejamento das aulas de Educação Física bastante comum (Introdução, Desenvolvimento e Volta à calma) com pequenas adequações. Assim, foi possível introduzir os conteúdos de forma contextualizada, realizar as atividades com segurança e finalizar a aula, obtendo a percepção dos alunos sobre o que foi trabalhado.

Para que as atividades ocorressem de maneira segura foram adotadas algumas precauções referentes a cada tipo de habilidade motora fundamental desenvolvida no programa. Estas precauções encontram-se no Quadro 2:

Quadro 2 - Precauções para desenvolvimento das atividades

\begin{tabular}{|c|l|}
\hline \multirow{2}{*}{ Atividades que envolvam: } & \multicolumn{1}{c|}{ CUIDADOS } \\
\hline \multirow{2}{*}{ Deslocamento } & $\begin{array}{l}\text { Fixação do aluno à cadeira de rodas por meio de cintos } \\
\text { e faixas. }\end{array}$ \\
\hline \multirow{3}{*}{ Manipulação } & Verificar autonomia ou necessidade de assistência. \\
\hline \multirow{2}{*}{ Transferências } & Liberar membros de apoio \\
\hline & Fixação de implementos com faixas \\
\hline & Atenção na utilização de objetos alergênicos \\
\hline & Apoio sob as articulaçães \\
\hline & Verificar conforto e tempo de permanência \\
\hline
\end{tabular}

Fonte: Munster (no prelo).

Em relação às precauções, devem ser consideradas as características dos participantes, bem como suas potencialidades e restrições médicas. Tais medidas devem ser tomadas com o intuito de obter maior controle sobre as atividades e evitar acidentes durante a realização das mesmas (GORGATTI, 2005; MAUERBERG-DECASTRO, 2005).

Dentre os conteúdos programáticos e estratégias para desenvolvimento das habilidades motoras fundamentais encontram-se os jogos cooperativos, brincadeiras, situações de jogos, jogos pré-desportivos, modalidades esportivas adaptadas, atividades cognitivas, jogos individuais e jogos musicais, desenvolvidas por meio de dinâmicas e aplicadas juntamente às estratégias supracitadas.

No quadro 3 são apresentados os conteúdos utilizados no programa de iniciação esportiva de crianças com deficiência física, bem como seus objetivos, estratégias, dinâmicas e alguns exemplos de aplicação.

Quadro 3 - Conteúdos para iniciação esportiva de crianças com deficiência física: objetivos, estratégias, dinâmicas

\begin{tabular}{|c|c|c|c|c|}
\hline TEMA & OBJETIVO & $\begin{array}{c}\text { ESTRATÉGIA } \\
\mathbf{S}\end{array}$ & DINÂMICAS & EXEMPLOS \\
\hline \multirow{5}{*}{$\begin{array}{l}\text { Iniciação ao } \\
\text { esporte }\end{array}$} & \multirow{5}{*}{$\begin{array}{l}\text { Desenvolver as } \\
\text { habilidades } \\
\text { motoras } \\
\text { fundamentais de } \\
\text { locomoção, } \\
\text { estabilização e } \\
\text { manipulação na } \\
\text { cadeira de rodas, } \\
\text { por meio dos } \\
\text { aspectos } \\
\text { pedagógicos e }\end{array}$} & $\begin{array}{l}\text { Jogos de } \\
\text { cooperação }\end{array}$ & \multirow{5}{*}{$\begin{array}{l}\text { *Atividades em } \\
\text { duplas e trios; } \\
\text { *Jogos } \\
\text { historiados; } \\
\text { *Construção das } \\
\text { atividades pelos } \\
\text { participantes; } \\
\text { *Execução e e } \\
\text { controle dos } \\
\text { movimentos; } \\
\text { *Utilização da }\end{array}$} & \multirow{5}{*}{$\begin{array}{l}\text { *Jogar } \\
\text { modalidades } \\
\text { esportivas coletivas } \\
\text { sobre cadeira de } \\
\text { rodas; } \\
\text { *Atividades } \\
\text { cooperação, onde } \\
\text { todos trabalham } \\
\text { como uma equipe. } \\
\text { *Criação de regras } \\
\text { do jogo pelos }\end{array}$} \\
\hline & & Brincadeiras & & \\
\hline & & $\begin{array}{c}\text { Situações de } \\
\text { jogo }\end{array}$ & & \\
\hline & & $\begin{array}{l}\text { Jogos pré- } \\
\text { desportivos }\end{array}$ & & \\
\hline & & $\begin{array}{c}\text { Jogos adaptados } \\
\text { a partir } \\
\text { das modalidades } \\
\text { convencionais }\end{array}$ & & \\
\hline
\end{tabular}




\begin{tabular}{|c|c|c|c|c|}
\hline & educacionais. & $\begin{array}{c}\text { Atividades } \\
\text { cognitivas } \\
\text { Jogos } \\
\text { individuais } \\
\text { Jogos musicais } \\
\text { Modalidades } \\
\text { esportivas em } \\
\text { cadeira de rodas } \\
\text { Do simples para } \\
\text { o mais } \\
\text { complexo }\end{array}$ & $\begin{array}{l}\text { musica como } \\
\text { elemento } \\
\text { desenvolvedor de } \\
\text { atenção } \\
\text { percepção } \\
\text { temporal. e } \\
\text { *Desenvolviment } \\
\text { o dos } \\
\text { fundamentos } \\
\text { comuns às } \\
\text { modalidades; }\end{array}$ & $\begin{array}{l}\text { próprios } \\
\text { participantes; } \\
\text { *Pegas; } \\
\text { *Estafetas; } \\
\text { *Drible; } \\
\text { *Deslocamento } \\
\text { entre obstáculos; } \\
\text { *Jogos com alvos e } \\
\text { zonas }\end{array}$ \\
\hline $\begin{array}{c}\text { Valores } \\
\text { comportamentai } \\
\text { s }\end{array}$ & $\begin{array}{c}\text { Ser capaz de } \\
\text { estabelecer } \\
\text { relações pessoais } \\
\text { de valor, tais como: } \\
\text { cooperação, } \\
\text { empatia e respeito } \\
\text { para o } \\
\text { desenvolvimento } \\
\text { de um jogo } \\
\text { coletivo, } \\
\text { estabelecendo } \\
\text { metáforas com a } \\
\text { vida. }\end{array}$ & $\begin{array}{l}\text { Interferência } \\
\text { verbal do } \\
\text { professor, } \\
\text { remetendo-se à } \\
\text { prática dos } \\
\text { alunos ou ao } \\
\text { livro didático. }\end{array}$ & $\begin{array}{c}\text { Ao longo das } \\
\text { atividades } \\
\text { práticas, } \\
\text { aproveitando as } \\
\text { situações surgidas } \\
\text { a fim de trabalhar } \\
\text { a importância do } \\
\text { respeito, } \\
\text { cooperação aos } \\
\text { demais } \\
\text { participantes. }\end{array}$ & $\begin{array}{l}\text { Utilizar-se das } \\
\text { possíveis } \\
\text { dificuldades } \\
\text { apresentadas pelos } \\
\text { participantes para } \\
\text { desenvolvimento } \\
\text { dos problemas do } \\
\text { jogo, bem como das } \\
\text { suas relações com } \\
\text { os demais durante as } \\
\text { atividades como } \\
\text { meio de destacar a } \\
\text { relevância dos } \\
\text { valores de respeito e } \\
\text { cooperação. }\end{array}$ \\
\hline
\end{tabular}

Fonte: Melo (2014).

Um programa de iniciação esportiva para crianças com deficiência física não deve restringir-se somente às modalidades esportivas adaptadas com o intuito de ensinar aspectos técnico-táticos. De acordo com Galatti, Paes e Darido (2010) deve possibilitar experiências envolvendo a diversificação motora. Existem outras componentes que também devem ser considerados essenciais para o desenvolvimento pedagógico e socioeducativo das crianças, como o respeito às regras e ao próximo, o trabalho em grupo, a ética e outros que vêm a ser desenvolvidos por meio das atividades. Nesse sentido, tão importante quanto organizar, sistematizar, aplicar e avaliar procedimentos pedagógicos para os componentes técnicotáticos dos Jogos Esportivos Coletivos (JECs) é fazê-lo em relação aos componentes sócioeducativos (GALATTI, PAES e DARIDO, 2010, p. 755).

Dentre os conteúdos abordados durante o decorrer das sessões do programa foram utilizados alguns fundamentos principais apresentados em basicamente todas as sessões do período de intervenção. Esses conteúdos e suas relações com as habilidades motoras encontram-se no Quadro 4. 
Quadro 4 - Relação dos conteúdos com as habilidades motoras

\begin{tabular}{|c|c|}
\hline HABILIDADE MOTORA & CONTEÚDO \\
\hline Locomoção & $\begin{array}{l}\text { Deslocamento na cadeira - Propulsão, mudança de direção; } \\
\text { Giro; Propulsão inversa. }\end{array}$ \\
\hline Manipulação & Passe; recepção; arremesso e drible. \\
\hline Estabilização & Equilíbrio estático e equilíbrio dinâmico. \\
\hline Habilidades Comb & $\begin{array}{l}\text { Locomoção com mudanças de direção; Drible } \\
\text { deslocamento; Arremesso em deslocamento; Passe em } \\
\text { deslocamento; Recepção em deslocamento. }\end{array}$ \\
\hline
\end{tabular}

Fonte: Melo (2014).

Os conteúdos utilizados possuem estreita relação com as habilidades motoras de locomoção, manipulação, estabilização, bem como a combinação das mesmas. Tais relações foram estabelecidas em meio ao processo de planejamento das sessões, considerando-se as peculiaridades da utilização da cadeira de rodas e suas habilidades, fazendo relações com a literatura de Gallahue e Ozmun, (2005).

\section{Estabelecimento das estratégias de ensino}

\section{Aulas em grupo}

As aulas foram desenvolvidas em grupo, uma vez que o programa tomou como base as características das modalidades esportivas coletivas que fazem uso da cadeira de rodas como dispositivo de locomoção, de forma a preservar as características de desenvolvimento de habilidades por meio das atividades coletivas, lúdicas e cooperativas. Como relatam Galatti e Paes (2007, p. 39):

Talvez a cultura esportiva nas modalidades individuais dificulte uma abordagem cooperativa, mas os jogos esportivos coletivos, por suas características exigem de seus participantes que, se não o tempo todo, em muitos momentos do jogo dediquem-se ao grupo; mesmo os jogadores tecnicamente acima da média, necessitam interar-se ao grupo, envolver-se e envolvê-lo, de forma que suas habilidades individuais estejam inseridas nas necessidades do grupo e os leve a atingir seus objetivos.

Portanto, durante o desenvolvimento da intervenção voltada à iniciação esportiva de crianças com deficiência física, buscou-se desenvolver atividades em grupo com a finalidade de possibilitar o aprendizado e/ou aprimoramento dos fundamentos das modalidades esportivas por meio da cooperação, aceitação e criação de regras.

\section{Progressão das atividades}

Durante a elaboração e sistematização do programa foram realizados estudos acerca de quais seriam as atividades desenvolvidas durante a intervenção, tendo em vista o curto período de duração do programa. Assim, foram utilizadas diversas atividades lúdicas e atrativas que proporcionassem aos participantes a aprendizagem por meio do brincar. No entanto, uma das estratégias principais foi o aumento gradual no nível de dificuldade das atividades, partindo de atividades mais elementares para, gradativamente, e de acordo com as necessidades e potencialidades de cada um dos participantes, atividades mais complexas. 


\section{Estilos de ensino}

São muitas as possibilidades de estratégias de ensino que podem ser adotadas para o ensino de crianças com deficiências físicas. No entanto, é fundamental recorrer ao espectro de estilos de ensino proposto por Muska Mosston, em 1966. Nesse modelo, são apresentados os estilos de ensino que apresentam diferentes características que podem servir como estratégias para atender as especificidades da clientela, gradualmente. São onze estilos, apresentados de A a K (MOSSTON; ASHWORTH, 2008): A. Comando; B. Tarefa; C. Recíproco; D. Autochecagem; E. Inclusão; F. Descoberta guiada; G. Solução de problemas (Convergente); H. Solução de problemas (Divergente); I. Programa individualizado; J. Iniciado pelo aluno; K. Autoensino.

A finalidade é ampliar as possibilidades pedagógicas dos professores e de enriquecer o processo de ensino-aprendizagem, tanto para os professores quanto para os alunos (HEINE, CARBINATTO E NUNOMURA, 2009). Para os autores, cada estilo de ensino, dentro do espectro, tem uma estrutura particular de decisões que tem impacto na relação de ensino entre o professor e o aluno.

Os estilos de ensino adotados nesse programa envolvem ensino por tarefas, por programação individualizada, bem como o estilo por descoberta guiada. No entanto não necessariamente os estilos foram utilizados em sua plenitude, mas as estratégias foram embasadas nesses estilos. Nesse sentido, o próprio Mosston (1966) ressalta que na teoria cada um desses estilos permanece separado, no entanto, na prática, muitos estilos de ensino podem coexistir, sendo difícil encontrar uma aplicação integral de um dos estilos enfatizados no espectro (MOURA, 2009).

\section{Conclusão}

Ainda são poucas as referências na literatura científica orientadas à elaboração de programas de Iniciação Esportiva voltadas ao público em questão: crianças com deficiências físicas. Com base na abordagem desenvolvimentista e evidências empíricas, foi desenvolvida e descrita uma programação de ensino pautada nos seguintes aspectos: 1. Diagnóstico da condição físico-motora dos participantes, visando identificar as características, interesses e necessidades especiais de cada um; 2. Apresentação e processo de adaptação dos participantes às cadeiras de rodas esportivas; 3 . Determinação dos objetivos e metas do programa; 4. Reconhecimento do espaço físico e condições de acessibilidade e permanência dos participantes no ambiente; 5. Seleção dos conteúdos programáticos; 6. Estabelecimento das estratégias de ensino adequadas às necessidades educacionais da clientela.

Destaca-se que foram mínimas as adaptações utilizadas nos conteúdos e estratégias, nas dinâmicas e atividades, as quais emergiram das características e necessidades dos participantes.

Foram aplicadas atividades diversificadas, de caráter cooperativo, com situações problema que possibilitassem a participação das crianças na concepção e desenvolvimento da atividade, atividades contextualizadas e historiadas, tendo como base as habilidades motoras voltadas aos fundamentos das modalidades esportivas, dos jogos e brincadeiras prédesportivas, adaptações de jogos e modalidades esportivas convencionais.

Em suma, a iniciação esportiva da criança com deficiência auxilia na experimentação do esporte em suas variadas formatações, devendo esse (o esporte) ser modificado para atingir as necessidades da criança e não o inverso. 


\title{
Agradecimentos
}

Agradecemos ao Conselho Nacional de Desenvolvimento Científico e Tecnológico (CNPq) pelo fomento e financiamento desse estudo.

\section{INITIATION TO WHEELCHAIR SPORTS: STRUCTURE OF A PROGRAM FOR CHILDREN WITH PHYSICAL DISABILITIES}

\begin{abstract}
This study aimed to describe a wheelchair sports initiation program to children with physical disabilities aged from six to ten years old. This is a descriptive study with empirical basis, through which was possible to obtain as results the structuring stages of the program, as the following details: understanding the physical motor condition of the participant; adaptation to the sports wheelchair; setting program goals; recognition of spaces; selection of the syllabus; planning teaching strategies; structure of classes. It was concluded that the assumptions adopted for the construction of sports initiation in wheelchair program proved to be suitable to the characteristics, needs and interests of the specific public.
\end{abstract}

Keywords: Physical Education. Sports Initiation. Physical Disability. Motor Skills.

\section{INICIACIÓN DEPORTIVA EN SILLA DE RUEDAS: ESTRUCTURACIÓN DE UN PROGRAMA PARA NIÑOS CON DISCAPACIDADES FÍSICAS}

\begin{abstract}
Resumen
El presente estudio tuvo como objetivo describir un programa de iniciación deportiva en silla de ruedas dirigida a niños con discapacidad física de 06 a 10 años. Se trata de un estudio descriptivo con base empírica, a través del cual fue posible obtener resultados en las etapas de estructuración del programa, como se detalla en la continuación: comprensión de la condición físico-motora del participante; adaptación a la silla de ruedas; establecimiento de los objetivos del programa; reconocimiento de los espacios; selección de contenidos del programa; planificación de las estrategias de enseñanza; estructura de clases. Se concluyó que los supuestos adoptados para la construcción del programa demostraron ser apropiados a las características, necesidades e intereses del público estudiado.

Palabras clave: Educación Física; Iniciación Deportiva; Discapacidad Física; Destrezas Motoras.
\end{abstract}

\section{Referências}

ARBOUR, K. P., LATIMER, A. E., MARTIN, G. K. A.; JUNG, M.E. Moving beyond the stigma: The impression formation benefits of exercise for individuals with a physical disability. Adapted Physical Activity Quarterly, Canadá, v. 24, n. 2, p. 144-159, 2007.

BATAVIA, M.; BATAVIA, A. I. FRIEDMAN, R. Changing chairs: anticipating problems in prescribing wheelchairs. disability and rehabilitation. New York, v. 23, n. 12, p. 539-548, 2001.

BOMPA, T. O. Treinamento total para jovens campeões. Barueri - SP: Manole, 2002. 249 p. 
CARVALHO, J. A. Órteses: um recurso terapêutico complementar. Barueri, SP: Manole, 2006, p. 170.

DI MARCO, A.; RUSSEL, M.; MASTERS, M. Standards for wheelchair prescription. Australian Occupational Therapy Journal, Melbourne, v. 50, n. 1, p. 30-39, 2003.

GALATTI, L. R; PAES, R. R. Pedagogia do esporte: iniciação ao basquetebol. Hortolândia: UNASP, 2007. 114p.

GALATTI, L. R.; PAES, R. R; DARIDO, S. C. Pedagogia do Esporte: livro didático aplicado aos Jogos Esportivos Coletivos. Motriz, Rio Claro, v.16 n.3 p.751-761, jul./set. 2010.

GAllahuE, D. L. OZMUN, J. C. Compreendendo o desenvolvimento motor: bebês, crianças, adolescentes e adultos. 3. ed. São Paulo: Phorte, 2005. 600p.

GORGATTI, M. G; COSTA R. F. Atividade Física Adaptada. Barueri, SP: Manole, 2005. 589 p.

GORGATtI, M. G. et al. Tendência competitiva no esporte adaptado. Arquivos Sanny de Pesquisa e Saúde, Santos, v.18, n.1, p.18-25, 2008.

HEINE, V.; CARBINATTO, M. V.; NUNOMURA, M. Estilos de ensino e a iniciação da capoeira para crianças de 7 a 10 anos de idade. Pensar a Prática, v.12, n.1, p.1-12, 2009.

HIGGS, C. Integration of Persons with a Disability in Canadian Sport. Canadian Sport for Life: Special report Canadian sport for life for athletes with a disability, Canadá, p.3-15, 2011.

LONGMUIR, P. E; BAR-OR, O. Factors influencing the physical activity levels of youth with physical and sensory disabilities. Adapted Physical Activity Quarterly, v. 17, n. 1, p. 40-53, 2000.

MARCONI, M. A.; LAKATOS, E. M. Técnicas de Pesquisa. 7. ed. São Paulo: Atlas, 2008, $282 \mathrm{p}$.

MARTIN, J. J. A personal development model of sport psychology for athletes withdisabilities. Journal of Applied Sport Psychology, v. 11, p. 181-193, 1999.

MARTIN, J. J. Psychosocial aspects of youth disability sport. Adapted Physical Activity Quarterly, 23, n. 1, p. 65-77, 2006.

MARTIN, J. J.; SMITH, K. Friendship quality in youth disability sport: Perceptions of a best friend. Adapted Physical Activity Quarterly, Canadá, 19, n. 4, p.472-482, 2002.

MAUERBERGDE, E. C. Atividade Física: adaptada. Ribeirão Preto, SP: Tecmedd, 2005. $555 \mathrm{p}$.

MELO, F. A. P. Influência de um programa de iniciação esportiva em crianças com deficiência física. 2014. 102f. Dissertação Parcial (Mestrado em Educação Especial) - 
Programa de Pós-Graduação em Educação Especial, Universidade Federal de São CarlosUFSCar, São Carlos, 2014.

MORAN, T. E. BLOCK, M. E. Barriers to Participation of Children with Disabilities in Youth Sports. Teaching Exceptional Children Plus. v. 6, n. 3, p 1-13, 2010.

MOURA, L. D. A Educação Física Escolar e os estilos de ensino: uma análise de duas escolas do Rio de Janeiro. Lecturas Educacíon Física y Deportes, Buenos Aires, v. 14, n. 137, 2009. Disponível em: <http://www.efdeportes.com/efd137/a-educacao-fisica-escolar-eos-estilos-de-ensino.htm>. Acesso em: 12 out. 2014.

MOSSTON, M. Teaching Physical Education. Columbus, C.E. Merril Books, 1966.

MOSSTON, M.; ASHWORTH, S. Teaching Physical Education. 1st online ed. Buckeystown, MD: Spectrum Institute for Teaching and Learning, 2008. 358p.

RIMMER, J. H., RILEY, B., WANG, E., \& RAUWORTH, A. Accessibility of health clubs for people with mobility disabilities and visual impairments. American Journal of Public Health, v. 95, n.11, p.2022-2028, 2005.

SERNAGLIA, M. B. DUARTE, E. DALlA DÉA V. H. Avaliação do autoconceito em cadeirantes praticantes de esporte adaptado. Pensar a Prática, Goiânia, v. 13, n. 3, p. 118, 2010.

SAMPIERI, R. H.; COLLADO, C. F. LUCIO, P. B. Metodologia de Pesquisa. 5. ed. São Paulo: McGraw-Hill, 2013. 624 p.

SHAPIRO, D. R. MARTIN, J. J. Multidimensional Physical Self-Concept of Athletes With Physical Disabilities. Adapted Physical Activity Quarterly, Canadá, v. 27, p. 294-307, 2010 .

Endereço para correspondência:

flavioedf06@yahoo.com.br

Flávio Anderson Pedrosa Melo

Rodovia Washington Luís, s/n

Jardim Guanabara

São Carlos - SP, 13565-905 